Article

\title{
Examination of the Spillover Effects among Natural Gas and Wholesale Electricity Markets Using Their Futures with Different Maturities and Spot Prices
}

\author{
Tadahiro Nakajima $^{1,2, *}$ and Yuki Toyoshima ${ }^{3}$ \\ 1 The Kansai Electric Power Company Incorporated, Osaka 530-8270, Japan \\ 2 Graduate School of Economics, Kobe University, Kobe 657-8501, Japan \\ 3 Shinsei Bank, Limited, Tokyo 103-8303, Japan; makenaizard@yahoo.co.jp \\ * Correspondence: nakajima.tadahiro@a4.kepco.co.jp
}

Received: 22 February 2020; Accepted: 23 March 2020; Published: 25 March 2020

\begin{abstract}
This study measures the connectedness of natural gas and electricity spot returns to their futures returns with different maturities. We employ the Henry Hub and the Pennsylvania, New Jersey, and Maryland (PJM) Western Hub Peak as the natural gas price indicator and the wholesale electricity price indicator, respectively. We also use each commodity's spot prices and 12 types of futures prices with one to twelve months maturities and realize results in fourfold. First, we observe mutual spillover effects between natural gas futures returns and learn that the natural gas futures market is integrated. Second, we observe the spillover effects from natural gas futures returns to natural gas spot returns (however, the same is not evident for natural gas spot returns to natural gas futures returns). We find that futures markets have better natural gas price discovery capabilities than spot markets. Third, we observe the spillover effects from natural gas spot returns to electricity spot returns, and the spillover effects from natural gas futures returns to electricity futures returns. We learn that the marginal cost of power generation (natural gas prices) is passed through to electricity prices. Finally, we do not observe any spillover effects amongst electricity futures returns, except for some combinations, and learn that the electricity futures market is not integrated.
\end{abstract}

Keywords: spillover effect; natural gas; electricity; spot; futures

\section{Introduction}

The main goal of this study is to clarify differences caused by maturity differences of natural gas and wholesale electricity futures, and differences between their spot and futures due to their commodity characteristics by examining the spillover effects among their futures with various maturities and spot markets. While we can expect the hypothesis of spillover from natural gas market to peak power market because natural gas is often marginal fuel, we can expect the hypothesis that there is no arbitrage trading among their futures and spot markets because we cannot store natural gas and electric energy easily. Moreover, this study might not only clarify the relationships between natural gas futures with one maturity and electricity futures with another maturity, but also reveal market integration by calculating the connectedness indexes among variables.

In the United States of America (USA) as of 2018, the share of electricity generation by fuel is as follows: natural gas is $35.4 \%$, coal $27.9 \%$, nuclear $19.0 \%$, hydroelectric and renewables $16.8 \%$, others $0.9 \%$, according to BP Statistical Review of World Energy 2019, $68^{\text {th }}$ edition [1]. These statistics imply that natural gas is the main fuel for power generation. Moreover, since the cost of procuring natural gas is the marginal cost of power generation, the relationship between the wholesale electricity market and the natural gas market is of great academic and practical interest. Because of this, many previous 
studies have empirically investigated the relationship between power prices and gas prices from various viewpoints using various methods. This section introduces only previous studies that have examined the North American market, as this study investigates the USA market.

Serletis and Herbert [2] examined the arbitraging mechanisms between the Henry Hub natural gas prices, the Transco Zone 6 (TZ6) natural gas prices, the New York Harbor heating oil, and the Pennsylvania, New Jersey, and Maryland (PJM) power prices. However, these authors showed that the power price series appear to be stationary, whereas both natural gas price series have the unit root. In other words, they argued that the arbitraging mechanism between the price of electricity and the other energies is not effective. Emery and Liu [3] found the cointegrated relationship between natural gas prices series and electricity prices series by examining both the southwestern USA power market and the Pacific Northwest USA power market. Moreover, they noted that natural gas is often the marginal fuel used to generate peak power. Woo et al. [4] investigated whether there is Granger-causality between the natural gas market and the electricity market in both Northern and Southern California. They argued that historical natural gas prices could significantly help predict future electricity prices. Serletis and Shahmoradi [5] examined the relationship between the Alberta gas and power in Canada to indicate the bidirectional causality. Brown and Yücel [6] revealed bidirectional causal nexus between natural gas prices and electricity prices in regional markets by analyzing both the northeastern and the southwestern USA markets. Mjelde and Bessler [7] studied dynamic price information flows among natural gas, uranium, coal, crude oil, and electricity. They showed price information flow from the two regional electricity peak markets to the natural gas market. Mohammadi [8] examined the long-run relation and short-run dynamics between retail electricity prices and three fossil fuel prices using annual data. The estimated long-run equation between electricity, coal, and natural gas prices is statistically significant. The parameters suggest a $1 \%$ rise in natural gas prices increases electricity prices by $0.622 \%$. The estimated vector error correction model indicates that natural gas prices Granger cause electricity prices, but not vice versa. Nakajima and Hamori [9] applied Toda and Yamamoto [10], and Cheung and Ng [11] to test the Granger-causal relationships between natural gas prices and electricity prices in the southern USA markets. The results show unidirectional causality in mean from the natural gas market to the electricity market. However, they found no causality in variance. Efimova and Serletis [12] investigated the relationships between fossil fuel and power price volatilities using multivariate generalized autoregressive conditional heteroskedasticity (GARCH) models. Alexopoulos [13] examined the performance of natural gas prices as a predictor for power prices at national and regional levels. They argued that, besides lower gas prices, the growing importance of gas as a predictor for power prices needs the existence of sufficient gas infrastructures and/or competitive market environments. Nakajima [14] examined whether profits can be earned by statistical arbitrage between natural gas futures and electricity futures on the assumption that power prices and natural gas prices have a cointegration relationship. The results of their spark-spread trading simulations show about $30 \%$ yield at maximum. However, to our knowledge, no study to date has measured the connectedness of electricity and natural gas spot returns to their futures returns at different maturities.

Diebold and Yilmaz [15] proposed the spillover index. This index can capture how the variables in a system are connected and can assess the shares of forecast error variation in each variable due to shocks of other variables. However, this approach is not the Granger-causality test. In essence, Diebold and Yilmaz's [15] approach only estimates how the variables mutually influence each other, and cannot assess whether the variables are significant enough to predict the other variables. Furthermore, the index was developed based on the vector moving average (VMA) representation of the vector autoregression (VAR) model. Therefore, we must confirm the stationarity of variables in order to adopt this technique.

Numerous studies have adopted Diebold and Yilmaz's [15] approach to analyze spillover effects in a wide variety of markets, not only traditional financial markets, but also commodity markets. However, only literature based on the energy market and published between 2019 and the present is 
presented henceforth. Yang [16] investigated the connection between international crude oil prices and economic policy uncertainty indexes of developed countries, namely, those of the USA, the United Kingdom (UK), Japan, Germany, France, and Italy. Singh et al. [17] analyzed the volatility spillover connectedness dynamics of crude oil and global asset indicators covering equity, commodities, bonds, and currency pairs. They adopted the West Texas Intermediate (WTI) futures prices as crude oil prices. The stock market indexes are the French CAC, the Japanese NKY, the Chinese SHCOMP, the USA's SPX, and the UK's UKX. Copper, gold, wheat, soybean, and corn are included by the commodities. The bonds include the USA's, the Japanese, the Chinese, the UK's, and the French 10-year indexes. The currency pairs are the EUR-to-USD, the JPY-to-USD, the GBP-to-USD, the CAD-to-USD, and the AUD-to-USD exchange rates. Pham [18] identified the degree and direction of connectedness between various clean energy stock indexes in order to examine whether all clean energy stocks respond homogeneously to crude oil prices. Jin et al. [19] measured the connectedness between the WTI crude oil, Bitcoin, and gold. Wang et al. [20] adopted the Diebold and Yilmaz [15] methodology as one of the approaches necessary to analyze the relationships between electricity, coal, natural gas, and crude oil in the European futures market. Husain et al. [21] calculated the connectedness among crude oil, palladium, titanium, gold, platinum, silver, steel, and the stock index. Albulescu et al. [22] presented the spillover estimates between the WTI crude oil, Australian dollar, Canadian dollar, South African rand, New Zealand dollar, Chilean peso, and the Brazilian real. Chen et al. [23] empirically analyzed the connectedness amongst the whole German power derivative markets. To address the large portfolio of markets in their study, the dynamic network approach can be combined with high-dimensional variable selection techniques. Scarcioffolo and Etienne [24] analyzed the spillover effects of the Northern American natural gas market using daily spot prices from seven locations in the USA and one location in Canada. Kang et al. [25] examined the connectedness among the five agriculture commodity price indexes (meat, dairy, cereals, vegetables, oils, and sugar) and international crude oil using monthly data. Malik and Umar [26] calculated the demand, supply, and risk shocks from crude oil futures prices by using the methodology proposed by Ready [27]. Then, they examined the connectedness among these three shocks, and exchange rates of major oil-exporting and oil-importing countries, namely the Brazilian real, Canadian dollar, Chinese yuan, Indian rupee, Japanese yen, Mexican peso, and Russian ruble. Song et al. [28] examined the dynamics of directional information spillover of returns and volatilities between fossil energy futures, renewable energy industry stocks, and investor sentiment. They selected the crude oil futures, natural gas futures, and coal futures for the fossil energy market. For the renewable energy stock market, they used the Wilder Hill Clean Energy Index, the S\&P Global Clean Energy Index, and the European Renewable Energy Index. As for investor sentiment, they utilized the Google search volume index of three keywords related to renewable energy in Google Trends, including "renewable energy," "solar energy," and "wind energy." Xiao et al. [29] studied the relationships among electricity markets of Poland, Germany, France, the Czech Republic, Portugal, Slovakia, Spain, Hungary, Italy, the UK, and northern Europe. Sun et al. [30] explored the price transmission mechanism from international crude oil to sub producer price indexes. They measured the connectedness among the spot prices of Brent crude oil and 15 Chinese sub-producer price indexes. Nakajima and Toyoshima [31] examined spillovers among the North American, European, and Asia-Pacific natural gas markets. He et al. [32] investigated the connectedness between natural gas and BRICS's (Brazil, Russia, India, China, and South Africa) exchange rate. Tiwari et al. [33] analyzed the connectedness between the Food Price Index, the Beverage Price Index, the Industrial Inputs Price Index, the Agricultural Raw Materials Index, the Metals Price Index, and the Fuel Price Index (which comprises crude oil, natural gas, and coal price indexes). Barbaglia et al. [34] studied the volatility spillovers between crude oil, natural gas, gasoline, ethanol, corn, wheat, soybean, sugar, cotton, and coffee futures prices. Guhathakurta et al. [35] studied the connectedness and directional spillover between cocoa, coffee, rubber, soybeans, soya oil, sugar, wheat, palm oil, oats, corn, aluminum, copper, silver, gold, palladium, platinum, and crude oil. Lovcha and Perez-Laborda [36] investigated the dynamic volatility connectedness between the Henry Hub natural gas futures and the WTI crude oil 
futures traded on the New York Mercantile Exchange (NYMEX). Zhang et al. [37] examined the return and volatility spillover among the natural gas, crude oil, and electricity utility stock indexes in North America and Europe.

This study applies Diebold and Yilmaz's [15] technique to the wholesale electricity market and the natural gas market. We measure the connectedness between power and gas spot returns and futures returns with different maturities. This study adopts the Henry Hub as the natural gas price indicator-one of the most representative natural gas price indexes-and the PJM Western Hub Peak as the wholesale electricity price indicator-which is both the most representative of wholesale power prices and is expected to be the strong link to natural gas prices as marginal cost. This study utilizes each commodity's spot prices and 12 types of futures with one to twelve months maturities. In other words, this study reveals not only the relationship between natural gas prices and wholesale electricity prices, but also the term structure of those prices by measuring the connectedness among these 26 variables.

The calculation results should be able to provide not only novel academic findings, but also useful information for practitioners. Especially, the results may be extremely informative for power generation companies, which hold huge spots and derivatives for both natural gas as raw material, and power as a product. The fluctuations in the price differences between gas and electricity causes concern for most practitioners. Their business risks are complicated because they conclude a variety of procurement and sales contracts, e.g. sales contracts at a fixed price, procurement contracts at prices linked to the other price indexes, and long-term contracts of 10 years or more. It is more efficient to comprehensively evaluate the risks of all contracts that they hold and to hedge their portfolio because it is more expensive to hedge each contract individually. Therefore, it is practical and significant to examine the spillover effects among natural gas and wholesale electricity markets using their futures prices with various different maturities and their spot prices. The relationships between the natural gas and electricity markets in various regions have been studied. However, there is no literature that analyzes the relationships between natural gas and electricity markets using their futures with more than 12 different maturities and their spot prices. Although we can analogize the hypothesis of spillover from the natural gas market to the electricity market from the previous literature, we can expect to discover some differences caused by different maturities of futures, and some differences between their spot and futures due to their commodity characteristics. The main goal of this study is to clarify these differences.

We can expect twofold results by measuring the spillover indexes between these variables. First, we can easily understand at a glance the general characteristics of the portfolio. Diebold and Yilmaz's [15] approach can quantify the degree to which price fluctuations of certain security components of a portfolio have an impact on the portfolio value. Second, we can grasp the market integration among these securities with ease. This approach can present the connectedness not only between any two variables, but also as a whole.

Our contribution to the literature is fourfold. This paper seeks to clarify the relationship and connectedness between natural gas and wholesale electricity markets' spot and futures with one to twelve months maturities. First, we explore the spillover effect of each spot market individually. The spillover effect from natural gas spot returns to electricity spot returns is larger than the spillover effect from gas spot returns to gas futures returns. We argue that the price return of natural gas spot has a greater effect on the price return of wholesale peak power spot, which is directly produced from gas, than on the price return of natural gas futures by arbitrage trading. On the other hand, we find spillover effects from natural gas futures markets to gas spot markets. We estimate that futures markets have better natural gas price discovery capabilities than spot markets. Because we do not observe any evident spillover effects from electricity spot returns to other variables or from all the futures returns to electricity spot returns, we conclude that power spot prices tend to be dependent on power supply and demand at that immediate time due to the limitations on arbitrage trading due to the non-storability of electricity. Second, we examine the spillover effects of natural gas futures markets. The mutual spillover effects between any gas futures are found. We indicate that the natural gas futures market 
is integrated. Third, we examine the relationships between the futures markets of gas and power. Our results show spillover effects from natural gas futures returns to power futures returns, which is consistent with previous studies that support Granger causality from natural gas prices to power prices. Conversely, we do not see notable spillover effects from electricity futures returns to natural gas futures returns. Finally, we explore the relationships between power futures markets. We confirm the presence of spillover effects only between the futures returns with maturity differences of six months. Therefore, we conclude that these effects are not caused by arbitrage trading and that the electricity futures market is not integrated. The maximum power load, which is the main determinant of the prices, has almost semi-annual seasonality. Therefore, we observe these spillover effects between six months differences maturities just as a single phenomenon.

The remainder of this paper is organized as follows: Section 2 describes the analyzed data, summary statistics, and preliminary basic analyses; Section 3 explains the adopted methodology; Section 4 presents the empirical results; Section 5 provides a summary of the findings and states the conclusions.

\section{Data and Preliminary Analyses}

\subsection{Data}

We adopt the Henry Hub as the natural gas price indicator in our study. Henry Hub is the name of a distribution hub of a natural gas pipeline system in the USA. The price of the natural gas delivered at that hub is the most referenced natural gas price. The Henry Hub futures are listed on the NYMEX.

As our wholesale electricity price indicator, we select the PJM Western Hub Peak. The PJM is one of the regional electricity transmission organizations that coordinates the generation and distribution of electricity in the USA. We use the peak load price series of the western hub in order to capture the relationship between natural gas and power. The PJM Western Hub Peak futures are listed on the NYMEX.

We obtained daily data from January 5, 2009, to December 31, 2018, from Bloomberg. Natural gas prices and electricity prices are cited in the United States dollars per million British thermal units (\$/MMBtu) and the United States dollars per megawatt hours (\$/MWh), respectively. We obtained each commodity's spot prices and 12 types of futures with one month to twelve months maturities. In other words, the relationships between 26 types of economic variables is analyzed.

Figure 1 shows time plots of natural gas prices. We observe that the fluctuations of all the price series are almost the same. However, only the natural gas spot price spiked in February 2014 and January 2018.

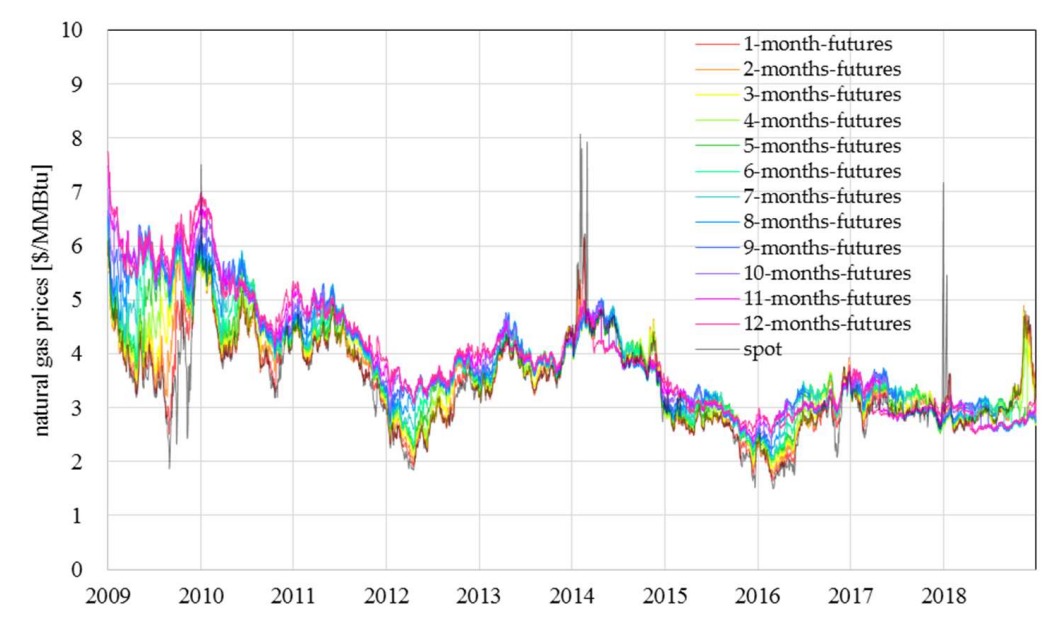

Figure 1. Time series plots of natural gas prices. (n-months-futures signifies futures with $n$ months maturity). 
The reason might be that the natural gas spot market temporally became very tight due to a cold temperature wave. Natural gas spots cannot be arbitraged easily with their futures. Therefore, sharp fluctuations in its supply and demand cause sharp price fluctuations.

Figure 2 shows the time plots of electricity prices. The relationship between the spot price and each futures price series is similar to that of the natural gas market. The fluctuations observed in all the price series are almost similar. However, only the spot price spikes frequently. Because the production and consumption of electricity occur concurrently, its supply stability requires simultaneous and equal amounts of power supply and demand. In other words, arbitrage between the spot prices and futures is practically impossible without the use of fuel for power generation. This causes the frequent spikes of the spot prices.

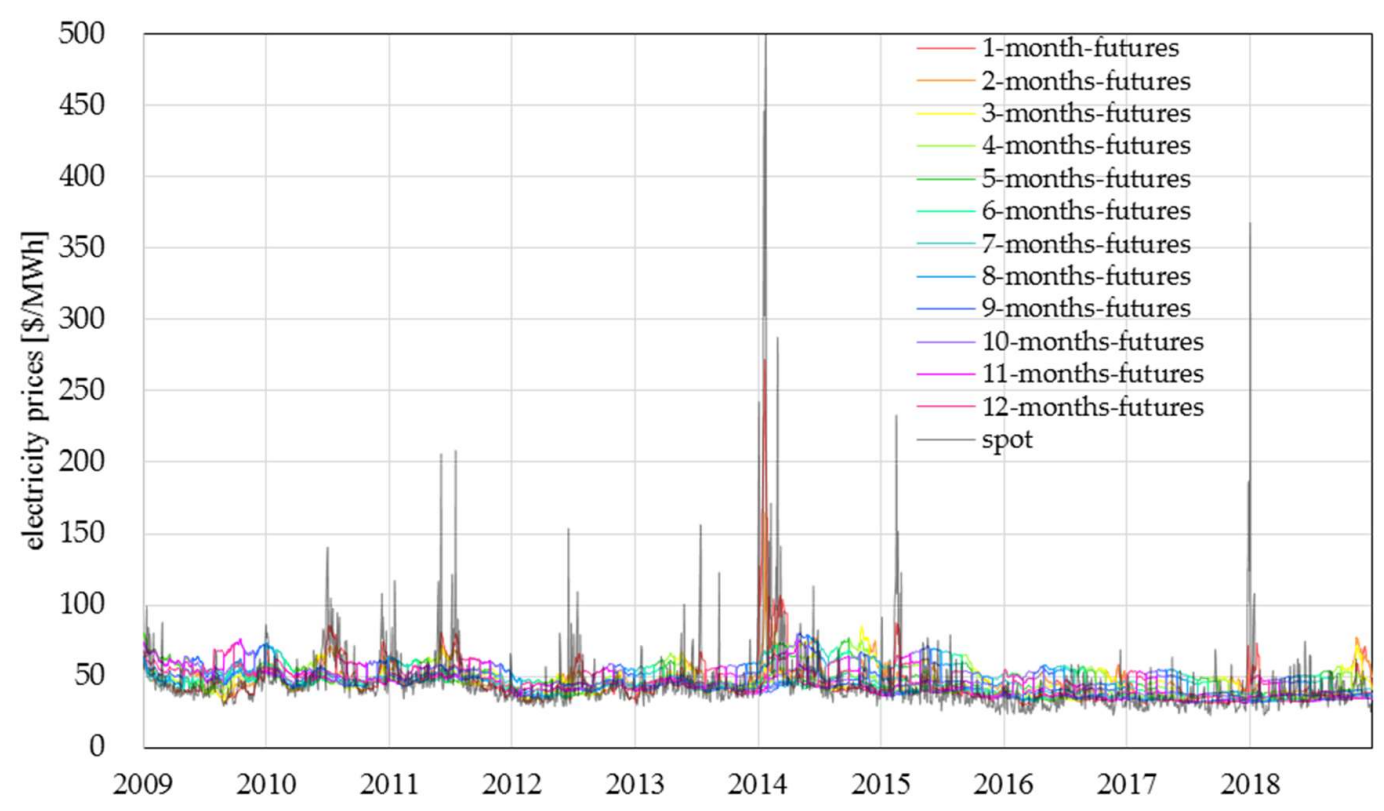

Figure 2. Time series plots of electricity prices. (n-months-futures signifies futures with $n$ months maturity).

Table 1 presents the summary statistics of each return series. There are 2452 observations in each case. The mean of all series are almost zero. All price series have no trend. In other words, loss from holding each security is equal to the risk-free interest cost. In the case of both natural gas and electricity, their spot prices have the outstanding largest maximum return and the outstanding smallest minimum return, compared to their futures. Therefore, only spot prices might fluctuate differently from the futures prices. The standard deviations of natural gas spot returns and electricity spot returns indicate the same. Each sign of skewness has no regularity and is both negative and positive. Most return series are right-skewed, whereas the return series of natural gas futures with four, nine, ten, eleven, and twelve months maturity and electricity futures with one month maturity are left-skewed. We find that all return series are fat-tailed, because their kurtoses have a positive value. Each kurtosis has no relationship with its maturity. The Jarque-Bera statistics calculated from the skewness and kurtosis of each series reject the hypothesis that each series is normally distributed.

\subsection{Preliminary Analyses}

To calculate Diebold and Yilmaz's [15] index, we need to convert the VAR model to a VMA representation with the condition that all variables remain stationary. Accordingly, we apply the augmented Dickey-Fuller (ADF) unit root test for all series. Table 2 presents the results. 
Table 1. Summary statistics of each return series of natural gas and electricity prices.

\begin{tabular}{crrrrrrr}
\hline Return Series & Mean & Maximum & Minimum & $\begin{array}{c}\text { Standard } \\
\text { Deviation }\end{array}$ & Skewness & Kurtosis & $\begin{array}{c}\text { Jarque-Bera } \\
(p \text {-Value) }\end{array}$ \\
\hline G0 & $0.0 \%$ & $70.1 \%$ & $-43.9 \%$ & $4.4 \%$ & 1.5 & 45.6 & $186,350(0)$ \\
G1 & $0.0 \%$ & $26.8 \%$ & $-18.1 \%$ & $3.1 \%$ & 0.6 & 8.3 & $2983(0)$ \\
G2 & $0.0 \%$ & $23.4 \%$ & $-22.6 \%$ & $2.8 \%$ & 0.3 & 9.3 & $4143(0)$ \\
G3 & $0.0 \%$ & $21.6 \%$ & $-20.2 \%$ & $2.6 \%$ & 0.4 & 9.7 & $4730(0)$ \\
G4 & $0.0 \%$ & $18.6 \%$ & $-37.7 \%$ & $2.5 \%$ & -1.0 & 30.9 & $79,780(0)$ \\
G5 & $0.0 \%$ & $21.7 \%$ & $-10.1 \%$ & $2.1 \%$ & 0.7 & 9.3 & $4291(0)$ \\
G6 & $0.0 \%$ & $19.3 \%$ & $-10.9 \%$ & $2.0 \%$ & 0.7 & 10.1 & $5398(0)$ \\
G7 & $0.0 \%$ & $13.7 \%$ & $-11.3 \%$ & $1.9 \%$ & 0.4 & 8.0 & $2661(0)$ \\
G8 & $0.0 \%$ & $11.6 \%$ & $-12.8 \%$ & $1.8 \%$ & 0.2 & 7.1 & $1721(0)$ \\
G9 & $0.0 \%$ & $13.2 \%$ & $-14.8 \%$ & $1.7 \%$ & -0.1 & 10.0 & $4954(0)$ \\
G10 & $0.0 \%$ & $12.2 \%$ & $-17.7 \%$ & $1.6 \%$ & -0.6 & 13.2 & $10,680(0)$ \\
G11 & $0.0 \%$ & $13.0 \%$ & $-17.2 \%$ & $1.6 \%$ & -0.7 & 15.4 & $15,992(0)$ \\
G12 & $0.0 \%$ & $11.9 \%$ & $-18.1 \%$ & $1.5 \%$ & -0.7 & 16.9 & $19,984(0)$ \\
\hline E0 & $0.0 \%$ & $203.2 \%$ & $-153.0 \%$ & $20.2 \%$ & 0.1 & 13.8 & $11,994(0)$ \\
E1 & $0.0 \%$ & $55.1 \%$ & $-67.0 \%$ & $5.3 \%$ & -0.8 & 42.4 & $158,546(0)$ \\
E2 & $0.0 \%$ & $46.7 \%$ & $-45.6 \%$ & $4.0 \%$ & 0.5 & 41.0 & $147,920(0)$ \\
E3 & $0.0 \%$ & $37.8 \%$ & $-30.1 \%$ & $3.4 \%$ & 1.9 & 43.2 & $166,958(0)$ \\
E4 & $0.0 \%$ & $46.1 \%$ & $-29.5 \%$ & $3.3 \%$ & 2.0 & 57.9 & $309,913(0)$ \\
E5 & $0.0 \%$ & $33.7 \%$ & $-30.7 \%$ & $3.1 \%$ & 1.1 & 48.1 & $208,672(0)$ \\
E6 & $0.0 \%$ & $40.4 \%$ & $-32.7 \%$ & $3.2 \%$ & 1.6 & 57.7 & $307,247(0)$ \\
E7 & $0.0 \%$ & $42.9 \%$ & $-37.5 \%$ & $3.3 \%$ & 1.4 & 63.4 & $373,262(0)$ \\
E8 & $0.0 \%$ & $44.7 \%$ & $-29.6 \%$ & $3.2 \%$ & 2.2 & 62.4 & $362,439(0)$ \\
E9 & $0.0 \%$ & $40.8 \%$ & $-27.1 \%$ & $3.1 \%$ & 1.8 & 58.1 & $311,279(0)$ \\
E10 & $0.0 \%$ & $39.8 \%$ & $-26.6 \%$ & $3.1 \%$ & 1.1 & 57.0 & $298,650(0)$ \\
E11 & $0.0 \%$ & $36.6 \%$ & $-28.9 \%$ & $3.0 \%$ & 0.7 & 56.3 & $290,411(0)$ \\
E12 & $0.0 \%$ & $33.2 \%$ & $-32.1 \%$ & $3.1 \%$ & 0.6 & 52.2 & $247,347(0)$ \\
\hline
\end{tabular}

Note: G0 signifies natural gas spot. Gn signifies natural gas futures with $n$ months maturity. E0 signifies electricity spot. En signifies electricity futures with $n$ months maturity.

Table 2. Unit root tests.

\begin{tabular}{ccc}
\hline \multirow{2}{*}{ Return Series } & \multicolumn{2}{c}{ Augmented Dickey-Fuller- $t$ Value ( $p$-Value) } \\
\cline { 2 - 3 } G0 & Exogenous: Constant & Exogenous: Constant, Trend \\
G1 & $-16.34(0.000)$ & $-16.34(0.000)$ \\
G2 & $-53.70(0.000)$ & $-53.69(0.000)$ \\
G3 & $-54.08(0.000)$ & $-54.08(0.000)$ \\
G4 & $-53.27(0.000)$ & $-53.27(0.000)$ \\
G5 & $-53.59(0.000)$ & $-53.59(0.000)$ \\
G6 & $-33.63(0.000)$ & $-33.62(0.000)$ \\
G7 & $-29.50(0.000)$ & $-29.50(0.000)$ \\
G8 & $-52.53(0.000)$ & $-52.52(0.000)$ \\
G9 & $-52.42(0.000)$ & $-52.41(0.000)$ \\
G10 & $-52.59(0.000)$ & $-52.59(0.000)$ \\
G11 & $-52.50(0.000)$ & $-52.50(0.000)$ \\
G12 & $-53.17(0.000)$ & $-53.18(0.000)$ \\
E0 & $-30.07(0.000)$ & $-30.09(0.000)$ \\
E1 & $-22.95(0.000)$ & $-22.95(0.000)$ \\
E2 & $-48.01(0.000)$ & $-48.00(0.000)$ \\
E3 & $-21.03(0.000)$ & $-21.03(0.000)$ \\
E4 & $-48.29(0.000)$ & $-48.28(0.000)$ \\
E5 & $-49.58(0.000)$ & $-49.57(0.000)$ \\
E6 & $-49.46(0.000)$ & $-49.45(0.000)$ \\
E7 & $-50.06(0.000)$ & $-50.05(0.000)$ \\
E8 & $-50.44(0.000)$ & $-50.43(0.000)$ \\
E9 & $-49.54(0.000)$ & $-49.53(0.000)$ \\
E10 & $-48.79(0.000)$ & $-48.78(0.000)$ \\
E11 & $-48.75(0.000)$ & $-48.74(0.000)$ \\
E12 & $-49.92(0.000)$ & $-49.91(0.000)$ \\
E1 & $-50.38(0.000)$ & $-50.38(0.000)$ \\
\hline
\end{tabular}

Note: G0 signifies natural gas spot. Gn signifies natural gas futures with $n$ months maturity. E0 signifies electricity spot. En signifies electricity futures with $n$ months maturity.

The ADF test rejects the null hypothesis that all variables are non-stationary. Therefore, we can confirm the availability of the VMA representation.

\section{Methodology}

We calculate the spillover index proposed by Diebold and Yilmaz [15] in order to capture the relationship between economic variables. This approach can reveal not only pairwise connectedness between any two variables, but also total connectedness between all variables. 
We consider the following covariance stationary twenty-six-variable VAR $(p)$ :

$$
r_{t}=\sum_{k=1}^{p} \Phi_{k} r_{t-k}+\varepsilon_{t}
$$

where $r_{t}$ is the twenty-six-dimensional vector of return, which must be a stationary series; $\Phi_{k}$ are the $26 \times 26$ coefficient matrices; $p$ is the lag length determined by minimizing the Schwarz information criterion; and $\varepsilon_{t}$ is an independently and identically distributed sequence of twenty-six-dimensional random vectors with zero mean and covariance matrix $\mathrm{E}\left(\varepsilon_{t} \varepsilon_{t}^{\prime}\right)=\Sigma$.

We can represent the above covariance stationary twenty-six-variable VAR model in the following VMA:

$$
r_{t}=\sum_{k=0}^{\infty} A_{k} \varepsilon_{t-k}
$$

where $A_{k}=\sum_{k=1}^{p} \Phi_{k} A_{t-k}, A_{0}$ being a $26 \times 26$ identity matrix with $A_{k}=0$ for $k<0$.

The spillover effect from the $l$ th to the $k$ th market up to $H$-step-ahead is defined as the following equation by using the $H$-step-ahead forecast error variance decompositions:

$$
\theta_{k l}=\frac{\sigma_{l l}^{-1} \sum_{h=0}^{H-1}\left(e_{k}^{\prime} A_{h} \Sigma e_{l}\right)^{2}}{\sum_{h=0}^{H-1} e_{k}^{\prime} A_{h} \Sigma A_{h}^{\prime} e_{k}}
$$

where $\sigma_{l l}$ is the standard deviation of the error term for the $l$ th equation and $e_{k}$ is the selection vector, with one as the $k$ th element and zeros otherwise.

Each entry of the variance decomposition matrix is normalized by the row sum, that is, 26 , as the pairwise connectedness:

$$
\widetilde{\theta_{k l}}=\frac{\theta_{k l}}{\sum_{l=1}^{26} \theta_{k l}}=\frac{\theta_{k l}}{26}
$$

The sum of pairwise connectedness is defined as total connectedness:

$$
S=\frac{\sum_{k=1}^{26} \sum_{l=1, k \neq l}^{26} \widetilde{\theta_{k l}}}{26}
$$

The numerator is the sum of the spillover effects. However, each spillover effect on itself is deducted. In other words, the total connectedness means the sum of the relative proportion of the portfolio's response to a shock.

Moreover, the directional spillover effects received by the $k$ th market from all other markets is measured as:

$$
S_{k}=\frac{\sum_{k=1, k \neq l}^{26} \widetilde{\theta_{k l}}}{26}
$$

Similarly, the directional spillover effects transmitted by the $k$ th market to all other markets is measured as:

$$
S_{\cdot k}=\frac{\sum_{k=1, k \neq l}^{26} \widetilde{\theta_{l k}}}{26}
$$

\section{Empirical Results}

Table 3 presents the spillover analysis results. This table shows total connectedness, all 676 ( $=26$ $\times 26)$ pairwise connectedness, all 26 directional spillover effects received from all other variables, and all 26 directional spillover effects transmitted to all other variables. The cells in this table are painted gradually from white to dark green, with white representing $0 \%$ and dark green representing $10 \%$ or more. 
Table 3. Spillover index (\%).

\begin{tabular}{|c|c|c|c|c|c|c|c|c|c|c|c|c|c|c|c|c|c|c|c|c|c|c|c|c|c|c|c|}
\hline \multirow{2}{*}{ To } & \multicolumn{27}{|c|}{ From } \\
\hline & G0 & G1 & G2 & G3 & G4 & G5 & G6 & G7 & G8 & G9 & G10 & G11 & G12 & E0 & E1 & E2 & E3 & $\mathrm{E} 4$ & E5 & E6 & E7 & E8 & E9 & E10 & E11 & E12 & Others \\
\hline G0 & 24.8 & 7.4 & 6.3 & 5.7 & 5.1 & 5.5 & 5.3 & 5.0 & 4.8 & 4.5 & 4.3 & 4.5 & 4.4 & 1.2 & 0.9 & 1.4 & 1.3 & 1.3 & 1.1 & 0.9 & 0.7 & 0.6 & 0.5 & 0.6 & 0.9 & 1.0 & 2.9 \\
\hline G1 & 0.7 & 10.5 & 9.5 & 8.5 & 7.0 & 7.1 & 6.9 & 6.8 & 6.6 & 6.1 & 5.7 & 5.6 & 6.0 & 0.0 & 0.8 & 2.2 & 2.0 & 1.5 & 1.0 & 1.0 & 1.2 & 0.9 & 0.7 & 0.7 & 0.5 & 0.6 & 3.4 \\
\hline G2 & 0.6 & 9.2 & 10.2 & 9.4 & 7.7 & 7.2 & 6.7 & 6.7 & 6.7 & 6.4 & 5.9 & 5.4 & 5.5 & 0.0 & 0.7 & 2.1 & 2.0 & 1.5 & 0.9 & 0.9 & 1.1 & 0.9 & 0.7 & 0.7 & 0.5 & 0.5 & 3.5 \\
\hline G3 & 0.6 & 8.2 & 9.4 & 10.1 & 8.7 & 7.8 & 6.7 & 6.5 & 6.5 & 6.5 & 6.3 & 5.6 & 5.1 & 0.0 & 0.6 & 1.7 & 1.9 & 1.5 & 0.9 & 1.0 & 1.1 & 0.9 & 0.7 & 0.7 & 0.5 & 0.5 & 3.5 \\
\hline G4 & 0.6 & 7.3 & 8.3 & 9.4 & 10.9 & 8.9 & 7.2 & 6.4 & 6.1 & 6.3 & 6.3 & 5.9 & 5.0 & 0.0 & 0.5 & 1.6 & 1.8 & 1.4 & 0.9 & 1.0 & 1.1 & 0.9 & 0.7 & 0.7 & 0.5 & 0.6 & 3.4 \\
\hline G5 & 0.5 & 6.7 & 7.0 & 7.6 & 8.1 & 10.0 & 9.0 & 7.6 & 6.6 & 6.2 & 6.5 & 6.6 & 6.2 & 0.0 & 0.5 & 1.4 & 1.5 & 1.3 & 0.9 & 1.0 & 1.2 & 1.0 & 0.7 & 0.7 & 0.6 & 0.6 & 3.5 \\
\hline G6 & 0.6 & 6.7 & 6.7 & 6.8 & 6.8 & 9.3 & 10.4 & 9.1 & 7.5 & 6.3 & 6.0 & 6.2 & 6.5 & 0.0 & 0.5 & 1.4 & 1.4 & 1.2 & 0.9 & 1.0 & 1.2 & 1.0 & 0.7 & 0.7 & 0.6 & 0.6 & 3.4 \\
\hline G7 & 0.5 & 6.8 & 6.9 & 6.7 & 6.1 & 8.0 & 9.2 & 10.5 & 9.0 & 7.3 & 6.2 & 5.6 & 6.1 & 0.0 & 0.5 & 1.5 & 1.4 & 1.1 & 0.9 & 1.0 & 1.2 & 1.0 & 0.7 & 0.7 & 0.6 & 0.6 & 3.4 \\
\hline G8 & 0.5 & 6.6 & 7.0 & 6.9 & 5.9 & 7.0 & 7.7 & 9.2 & 10.6 & 8.9 & 7.3 & 5.8 & 5.4 & 0.0 & 0.5 & 1.5 & 1.4 & 1.1 & 0.9 & 1.0 & 1.3 & 1.0 & 0.7 & 0.7 & 0.6 & 0.6 & 3.4 \\
\hline G9 & 0.5 & 6.3 & 6.8 & 6.9 & 6.2 & 6.7 & 6.6 & 7.6 & 9.0 & 10.8 & 8.9 & 7.0 & 5.6 & 0.0 & 0.4 & 1.5 & 1.4 & 1.2 & 0.9 & 1.0 & 1.2 & 1.0 & 0.7 & 0.7 & 0.6 & 0.6 & 3.4 \\
\hline G10 & 0.5 & 5.9 & 6.4 & 6.8 & 6.3 & 7.2 & 6.4 & 6.5 & 7.5 & 9.0 & 11.0 & 8.5 & 6.8 & 0.0 & 0.4 & 1.4 & 1.4 & 1.2 & 1.0 & 1.0 & 1.2 & 0.9 & 0.7 & 0.7 & 0.6 & 0.6 & 3.4 \\
\hline G11 & 0.5 & 6.0 & 6.1 & 6.3 & 6.2 & 7.6 & 6.9 & 6.2 & 6.3 & 7.4 & 9.0 & 11.5 & 8.8 & 0.0 & 0.4 & 1.4 & 1.4 & 1.2 & 1.0 & 0.9 & 1.2 & 1.0 & 0.7 & 0.8 & 0.6 & 0.6 & 3.4 \\
\hline G12 & 0.6 & 6.8 & 6.4 & 6.0 & 5.5 & 7.5 & 7.6 & 7.0 & 6.1 & 6.3 & 7.5 & 9.2 & 12.1 & 0.0 & 0.4 & 1.5 & 1.5 & 1.2 & 0.9 & 0.9 & 1.2 & 1.0 & 0.8 & 0.8 & 0.6 & 0.6 & 3.4 \\
\hline E0 & 3.4 & 0.2 & 0.2 & 0.2 & 0.2 & 0.2 & 0.2 & 0.3 & 0.3 & 0.3 & 0.3 & 0.2 & 0.2 & 88.2 & 3.0 & 0.6 & 0.2 & 0.2 & 0.3 & 0.1 & 0.2 & 0.1 & 0.2 & 0.2 & 0.2 & 0.2 & 0.5 \\
\hline E1 & 0.6 & 3.7 & 3.3 & 2.9 & 2.4 & 2.4 & 2.5 & 2.3 & 2.1 & 2.0 & 2.0 & 1.9 & 2.7 & 1.9 & 49.1 & 8.9 & 1.0 & 0.1 & 0.2 & 0.7 & 5.6 & 0.8 & 0.1 & 0.5 & 0.0 & 0.3 & 2.0 \\
\hline E2 & 0.0 & 6.1 & 5.9 & 4.6 & 3.8 & 3.9 & 4.0 & 4.5 & 4.2 & 3.7 & 3.5 & 3.4 & 3.6 & 0.1 & 4.8 & 27.3 & 5.4 & 0.3 & 0.0 & 0.0 & 1.4 & 7.8 & 0.9 & 0.1 & 0.5 & 0.0 & 2.8 \\
\hline E3 & 0.3 & 5.0 & 5.6 & 5.2 & 4.1 & 3.6 & 3.2 & 3.6 & 4.3 & 4.0 & 3.2 & 3.1 & 3.1 & 0.1 & 0.5 & 4.8 & 24.0 & 4.6 & 0.2 & 0.5 & 0.1 & 0.8 & 12.3 & 2.0 & 0.6 & 1.3 & 2.9 \\
\hline E4 & 0.5 & 3.9 & 4.1 & 4.6 & 4.2 & 3.4 & 3.2 & 3.2 & 3.1 & 3.9 & 3.9 & 3.0 & 2.9 & 0.1 & 0.0 & 0.2 & 5.2 & 26.6 & 3.6 & 0.6 & 0.8 & 0.5 & 1.5 & 14.4 & 1.6 & 1.0 & 2.8 \\
\hline E5 & 0.6 & 3.1 & 3.0 & 3.1 & 3.2 & 3.4 & 2.8 & 3.4 & 3.5 & 2.8 & 3.8 & 3.9 & 2.5 & 0.1 & 0.1 & 0.1 & 0.3 & 4.2 & 31.8 & 2.2 & 0.7 & 0.9 & 0.6 & 1.7 & 17.1 & 1.0 & 2.6 \\
\hline E6 & 0.3 & 2.9 & 3.3 & 3.2 & 2.8 & 3.7 & 3.4 & 2.9 & 3.8 & 4.1 & 2.7 & 3.1 & 2.9 & 0.0 & 0.5 & 0.1 & 0.6 & 0.7 & 2.1 & 30.7 & 3.9 & 0.7 & 1.9 & 0.5 & 1.4 & 17.7 & 2.7 \\
\hline E7 & 0.1 & 3.6 & 3.6 & 3.8 & 3.3 & 4.1 & 4.8 & 4.6 & 3.8 & 4.3 & 4.8 & 3.4 & 4.1 & 0.0 & 3.6 & 1.7 & 0.1 & 1.0 & 0.7 & 4.1 & 32.2 & 2.2 & 1.5 & 2.0 & 0.2 & 2.3 & 2.6 \\
\hline E8 & 0.1 & 3.5 & 3.3 & 3.0 & 2.8 & 3.3 & 3.9 & 5.1 & 4.4 & 3.2 & 3.5 & 4.0 & 3.0 & 0.0 & 0.6 & 9.9 & 1.2 & 0.7 & 1.0 & 0.7 & 2.3 & 34.0 & 2.0 & 2.1 & 2.1 & 0.3 & 2.5 \\
\hline E9 & 0.1 & 2.6 & 3.0 & 2.8 & 2.2 & 2.4 & 2.2 & 2.9 & 4.0 & 3.6 & 2.3 & 2.6 & 2.7 & 0.0 & 0.1 & 1.1 & 16.8 & 1.9 & 0.6 & 2.1 & 1.6 & 2.0 & 32.8 & 2.6 & 2.4 & 2.8 & 2.6 \\
\hline E10 & 0.5 & 2.2 & 2.4 & 2.7 & 2.3 & 2.4 & 2.4 & 2.5 & 2.5 & 3.5 & 3.5 & 2.3 & 2.7 & 0.1 & 0.3 & 0.1 & 2.7 & 17.9 & 1.8 & 0.6 & 2.1 & 2.0 & 2.7 & 33.1 & 2.8 & 1.9 & 2.6 \\
\hline E11 & 0.9 & 2.3 & 1.9 & 2.0 & 2.0 & 2.1 & 2.0 & 2.5 & 2.4 & 2.1 & 3.5 & 3.4 & 1.8 & 0.1 & 0.0 & 0.7 & 0.9 & 2.2 & 19.3 & 1.6 & 0.2 & 2.2 & 2.6 & 3.0 & 36.0 & 2.4 & 2.5 \\
\hline E12 & 0.6 & 2.4 & 2.7 & 2.2 & 1.8 & 2.4 & 2.2 & 2.1 & 2.9 & 2.8 & 2.0 & 2.9 & 2.6 & 0.1 & 0.2 & 0.1 & 1.9 & 1.3 & 1.1 & 20.3 & 2.5 & 0.3 & 3.0 & 2.1 & 2.4 & 35.3 & 2.5 \\
\hline Others & 0.6 & 4.8 & 5.0 & 4.9 & 4.4 & 4.9 & 4.7 & 4.8 & 4.8 & 4.7 & 4.6 & 4.4 & 4.1 & 0.2 & 0.8 & 1.9 & 2.2 & 2.0 & 1.7 & 1.8 & 1.4 & 1.2 & 1.5 & 1.5 & 1.5 & 1.5 & 75.6 \\
\hline
\end{tabular}

Note: G0 signifies natural gas spot. Gn signifies natural gas futures with $n$ months maturity. E0 signifies electricity spot. En signifies electricity futures with $n$ months maturity. 


\subsection{Between Spot and Others}

We cannot find spillover effects from natural gas spot returns to the other variables except for electricity spot returns (see column G0 of Table 3). The pairwise connectedness from gas spot returns to power spot returns is $3.4 \%$ (see row E0 and column G0 in Table 3). We estimate that it is practically difficult to arbitrage gas and electricity futures markets by renting or lending the cash position of natural gas. Due to the quantitative and cost constraints for storing natural gas, natural gas spot prices are more likely to be transmitted to natural gas-fueled peak electricity spot prices than natural gas futures.

The spillover effects from all the gas futures returns to gas spot returns are observed (see row G0 and columns G1 to G12 in Table 3). Although the spot market is susceptible to irregular trading and momentary fluctuations in its supply and demand, the futures markets have enough time to reflect the information related to its price formation, as long as its liquidity is high. Therefore, futures markets have better natural gas price discovery capabilities than spot markets. The pairwise spillover index from electricity futures returns with each maturity to natural gas spot returns is small.

No spillover effects from electricity spot returns to the other variables (see row E0 in Table 3) and from all the futures returns to electricity spot returns occur (see row E0 in Table 3). Electricity spot prices are dependent on the power generation costs and the power market conditions at that time because the non-storability of electricity limits arbitrage trading.

Nakajima [38] and Moutinho et al. [39] examined the relationship between natural gas and wholesale electricity spot prices in Japan and Spain, respectively. Their results reject the hypothesis of the Granger causality between gas and power prices. We cannot argue that the pairwise connectedness indicators between gas and electricity spot returns are consistent with Nakajima [38] and Moutinho et al. [39]. This is assumed to be due to differences between Granger causality and spillover effects and/or regional differences.

\subsection{Between Natural Gas Futures}

The pairwise spillover indexes between any natural gas futures returns are over $5 \%$, while the spillover effect from each natural gas futures return to itself is about 11\% (see rows G1 to G12 and columns G1 to G12 in Table 3). In other words, the natural gas futures market is mostly integrated. Especially, the gas futures markets with a month maturity and with two months maturity are perfectly integrated, because the spillover indexes from these futures returns to themselves are $10.5 \%$ (see row G1 and column G1 in Table 3) and 10.2\% (see row G2 and column G2 in Table 3), while the indexes from themselves to each other are 9.2\% (see row G1 and column G2 in Table 3) and 9.5\% (see row G2 and column G1 in Table 3). Furthermore, the spillover effect indexes between futures returns with close maturity differences tend to be greater than those between futures returns with long maturity differences.

\subsection{Between Natural Gas Futures and Electricity Futures}

We can observe the spillover effects from natural gas futures returns with each maturity to wholesale electricity futures returns with each maturity (see rows E1 to E12 and columns G1 to G12 in Table 3). These calculated results are consistent with previous studies that conclude a Granger causality from natural gas prices to power prices (see Emery and Liu [3] which is one of the most representative previous studies which examines the relationship between natural gas and electricity futures prices). The pairwise spillover indexes from the natural gas futures returns to the electricity futures returns with around the same maturity are larger. The natural gas futures prices with certain maturity affect not only the natural gas futures prices with other maturities, but also the peak power futures prices. The pairwise spillover index from the natural gas futures returns with a one-month period maturity to the wholesale electricity futures returns with a two-month period maturity is 6.1\% (see row E2 and column G1 in Table 3). 
Conversely, spillover effects from electricity futures to natural gas futures are hardly found (see rows G1 to G12 and columns E1 to E12 in Table 3). The maximum is the pairwise index from the electricity futures returns with a two-month maturity period to natural gas futures returns with a one-month maturity period, which is only $2.2 \%$ (see row G1 and column E2 in Table 3). The relatively accurate forecast of electricity demand after two months might affect not only the peak power futures prices but also the fuel futures.

\subsection{Between Electricity Futures}

We cannot confirm spillover effects between wholesale electricity futures returns, except for the spillover effects between futures returns with maturity differences of six months (see rows E1 to E12 and columns E1 to E12 in Table 3). We should interpret these results by understanding the relationship between the futures price formation and the features of this commodity differently from traditional financial securities.

Futures prices are primarily the expected prices at maturity. However, we should consider arbitrage trading in the spot market. By considering the cost of carrying over the spot position to the maturity of the futures including the opportunity costs and the risk of holding the spot position, we can obtain a non-arbitrage conditional equation for the spot prices and the futures prices. Using this equation, each spot price gives us a unique futures price. However, electricity is a good that is consumed at the same time that it is produced meaning we cannot store electric energy easily. In other words, arbitrage between the electricity spot market and futures markets is practically impossible. Spread trading between futures markets with different maturities is impossible as well, although we cannot deny electricity arbitrage trading through the fuel markets.

On the other hand, the main determinant of electricity prices is the load at that time. Therefore, peak power prices are affected by maximum power loads, which have almost semi-annual seasonality. Table 4 presents the correlation coefficients between the monthly average values of the daily maximum loads. The correlation coefficient between six-month differences is close to one. Moreover, we calculate the correlation coefficients between electricity futures of different maturity to understand the simultaneous relationship as a phenomenon. In Table 5, which shows those coefficients, we observe that the correlation coefficients between six-month differences are relatively large. The cells in this table are painted gradually from white to green, with white representing 0 and dark green representing 1.

Table 4. Correlation coefficients between maximum loads.

\begin{tabular}{ccccccc}
\hline Months Difference & $\mathbf{1}$ & $\mathbf{2}$ & $\mathbf{3}$ & $\mathbf{4}$ & $\mathbf{5}$ & $\mathbf{6}$ \\
\hline Correlation coefficients & 0.32 & -0.35 & -0.88 & -0.37 & 0.38 & 0.80 \\
\hline
\end{tabular}

Table 5. Correlation coefficients between electricity futures.

\begin{tabular}{|c|c|c|c|c|c|c|c|c|c|c|c|c|}
\hline Return Series & E1 & E2 & E3 & E4 & E5 & E6 & E7 & E8 & E9 & E10 & E11 & E12 \\
\hline E1 & 1.00 & & & & & & & & & & & \\
\hline E2 & 0.43 & 1.00 & & & & & & & & & & \\
\hline E3 & 0.05 & 0.42 & 1.00 & & & & & & & & & \\
\hline E4 & -0.10 & -0.05 & 0.41 & 1.00 & & & & & & & & \\
\hline E5 & -0.01 & -0.22 & -0.21 & 0.39 & 1.00 & & & & & & & \\
\hline E6 & 0.15 & -0.06 & -0.33 & -0.24 & 0.32 & 1.00 & & & & & & \\
\hline E7 & 0.40 & 0.29 & -0.15 & -0.37 & -0.25 & 0.37 & 1.00 & & & & & \\
\hline E8 & 0.17 & 0.63 & 0.24 & -0.24 & -0.39 & -0.24 & 0.33 & 1.00 & & & & \\
\hline E9 & -0.10 & 0.22 & 0.77 & 0.25 & -0.25 & -0.42 & -0.27 & 0.30 & 1.00 & & & \\
\hline E10 & -0.20 & -0.14 & 0.31 & 0.79 & 0.29 & -0.23 & -0.43 & -0.31 & 0.32 & 1.00 & & \\
\hline E11 & -0.10 & -0.30 & -0.20 & 0.32 & 0.79 & 0.24 & -0.23 & -0.44 & -0.30 & 0.36 & 1.00 & \\
\hline E12 & 0.10 & -0.11 & -0.39 & -0.23 & 0.29 & 0.81 & 0.28 & -0.24 & -0.45 & -0.28 & 0.32 & 1.00 \\
\hline
\end{tabular}

Note: En signifies electricity futures with $n$ months maturity. 
Therefore, we should interpret these spillover effects between six-month maturity differences just as a seasonal phenomenon. The electricity futures market cannot be considered integrated.

\section{Conclusions}

We have adopted Diebold and Yilmaz's [15] approach to examine the spillover effects among natural gas and wholesale electricity markets using their futures with different maturities and their spot prices. We used daily data from January 5, 2009, to December 31, 2018, and employed the Henry Hub and the PJM Western Hub Peak as the natural gas price indicator and the wholesale electricity price indicator, respectively. We obtained each commodity's spot prices and 12 types of futures with one to twelve months maturities. In other words, we analyzed the relationships between 26 types of economic variables.

The main results of our analyses are fourfold. First, we find that there are mutual spillover effects amongst natural gas futures returns showing that the natural gas futures market is integrated. The possession of futures with many different maturities has a low diversification effect on a portfolio, although it is effective for directly hedging the spot trading at the applicable maturity. It is reasonable to hold the futures with two-, three-, and four-month period maturities, because these futures largely affect the other variables (see the row Others and columns G2 to G4 in Table 3) and all futures are equally affected by the other variables (see rows G1 to G12 and the column Others in Table 3).

Second, our results show that there are spillover effects from natural gas futures returns to natural gas spot returns, although no spillover effects from natural gas spot returns to natural gas futures returns are evident. From this, we conclude that futures markets have better natural gas price discovery capabilities than spot markets. The natural gas futures markets indicate the prices expected from the long-term economic environment surrounding natural gas. The natural gas spot prices often deviate from their fundamentals because the storage cost is extremely expensive, and the spot prices depend on their fluctuations in supply and demand at that immediate time. Therefore, the futures prices must be utilized when formulating government policies and/or business plans.

Third, we observe spillover effects from natural gas spot returns to electricity spot returns as well as spillover effects from natural gas futures returns to electricity futures returns. The spillover effects from natural gas spot returns to electricity spot returns are larger than the spillover effect from natural gas spot returns to natural gas futures returns. We thus argue that the marginal cost of power generation (natural gas prices) is passed through to electricity prices. The natural gas futures markets are extremely useful in order to control the risks from the electricity markets.

Finally, our results do not show any spillover effects amongst electricity futures returns, except for some combinations, or any spillover effects from electricity futures returns to natural gas futures returns. We confirm the presence of spillover effects between futures with a maturity difference of six months only, concluding these as merely a singular phenomenon. This means it is not caused by arbitrage trading. The maximum power load, which is the main determinant of the prices, has an almost semi-annual seasonality. Thus, we conclude that the electricity futures market is not integrated. We might expect diversification effects by the possession of the futures with many different maturities. However, it is necessary to pay attention to the seasonality in the selection.

Author Contributions: Conceptualization, T.N.; Data curation, T.N.; Formal analysis, T.N.; Validation, Y.T.; Visualization, T.N.; Writing—original draft, T.N.; Writing—review \& editing, T.N. All authors have read and agreed to the published version of the manuscript.

Funding: This research received no external funding.

Acknowledgments: The authors would like to thank the anonymous reviewers, whose valuable comments helped improve an earlier version of this paper.

Conflicts of Interest: The authors declare no conflicts of interest. 


\section{References}

1. BP p.l.c., 1 St James's Square, London SW1Y 4PD, UK. BP's Statistical Review of World Energy 2019, 68th ed. Available online: https://www.bp.com/content/dam/bp/business-sites/en/global/corporate/pdfs/energyeconomics/statistical-review/bp-stats-review-2019-full-report.pdf (accessed on 4 February 2020).

2. Serletis, A.; Herbert, J. The message in North American energy prices. Energy Econ. 1999, 21, 471-483. [CrossRef]

3. Emery, G.W.; Liu, W.Q. An analysis of the relationship between electricity and natural-gas futures prices. J. Futures Mark. 2002, 22, 95-122. [CrossRef]

4. Woo, C.; Olson, A.; Horowitz, I.; Luk, S. Bi-directional causality in California's electricity and natural-gas markets. Energy Policy 2006, 34, 2060-2070. [CrossRef]

5. Serletis, A.; Shahmoradi, A. Measuring and testing natural gas and electricity markets volatility: Evidence from Alberta's deregulated markets. Stud. Nonlinear Dyn. Econ. 2006, 10, 10. [CrossRef]

6. Brown, S.P.A.; Yücel, M.K. Deliverability and regional pricing in U.S. natural gas markets. Energy Econ. 2008, 30, 2441-2453. [CrossRef]

7. Mjelde, J.W.; Bessler, D.A. Market integration among electricity markets and their major fuel source markets. Energy Econ. 2009, 31, 482-491. [CrossRef]

8. Mohammadi, H. Electricity prices and fuel costs: Long-run relations and short-run dynamics. Energy Econ. 2009, 31, 503-509. [CrossRef]

9. Nakajima, T.; Hamori, S. Testing causal relationships between wholesale electricity prices and primary energy prices. Energy Policy 2013, 62, 869-877. [CrossRef]

10. Toda, H.Y.; Yamamoto, T. Statistical inference in vector autoregressions with possibly integrated processes. J. Econ. 1995, 66, 225-250. [CrossRef]

11. Cheung, Y.W.; Ng, L.K. A causality-in-variance test and its application to financial market prices. J. Econ. 1996, 72, 33-48. [CrossRef]

12. Efimova, O.; Serletis, A. Energy markets volatility modelling using GARCH. Energy Econ. 2014, 43, $264-273$. [CrossRef]

13. Alexopoulos, T.A. The growing importance of natural gas as a predictor for retail electricity prices in USA. Energy 2017, 137, 219-233. [CrossRef]

14. Nakajima, T. Expectations for statistical arbitrage in energy futures markets. J. Risk Financ. Manag. 2019, 12, 14. [CrossRef]

15. Diebold, F.X.; Yilmaz, K. Better to give than to receive: Predictive directional measurement of volatility spillovers. Int. J. Forecast. 2012, 28, 57-66. [CrossRef]

16. Yang, L. Connectedness of economic policy uncertainty and oil price shocks in a time domain perspective. Energy Econ. 2019, 80, 219-233. [CrossRef]

17. Singh, V.K.; Kumar, P.; Nishant, S. Feedback spillover dynamics of crude oil and global assets indicators: A system-wide network perspective. Energy Econ. 2019, 80, 321-335. [CrossRef]

18. Pham, L. Do all clean energy stocks respond homogeneously to oil price? Energy Econ. 2019, 81, 355-379. [CrossRef]

19. Jin, J.; Yu, J.; Hu, Y.; Shang, Y. Which one is more informative in determining price movements of hedging assets? Evidence from Bitcoin, gold and crude oil markets. Phys. A 2019, 527, 121121. [CrossRef]

20. Wang, B.; Wei, Y.; Xing, Y.; Ding, W. Multifractal detrended cross-correlation analysis and frequency dynamics of connectedness for energy futures markets. Phys. A 2019, 527, 121194. [CrossRef]

21. Husain, S.; Tiwari, A.K.; Sohag, K.; Shahbaz, M. Connectedness among crude oil prices, stock index and metal prices: An application of network approach in the USA. Resour. Policy 2019, 62, 57-65. [CrossRef]

22. Albulescu, C.T.; Demirer, R.; Raheem, I.D.; Tiwari, A.K. Does the U.S. economic policy uncertainty connect financial markets? Evidence from oil and commodity currencies. Energy Econ. 2019, 83, 375-388. [CrossRef]

23. Chen, S.; Härdle, W.K.; Cabrera, B.L. Regularization approach for network modeling of German power derivative market. Energy Econ. 2019, 83, 180-196. [CrossRef]

24. Scarcioffolo, A.R.; Etienne, X.L. How connected are the U.S. regional natural gas markets in the post-deregulation era? Evidence from time-varying connectedness analysis. J. Commod. Mark. 2019, 15, 100076. [CrossRef] 
25. Kang, S.H.; Tiwari, A.K.; Albulescu, C.T.; Yoon, S.M. Exploring the time-frequency connectedness and network among crude oil and agriculture commodities V1. Energy Econ. 2019, 84, 104543. [CrossRef]

26. Malik, F.; Umar, Z. Dynamic connectedness of oil price shocks and exchange rates. Energy Econ. 2019, 84, 104501. [CrossRef]

27. Ready, R.C. Oil Prices and the Stock Market. Rev. Financ. 2018, 22, 155-176. [CrossRef]

28. Song, Y.; Ji, Q.; Du, Y.; Geng, J. The dynamic dependence of fossil energy, investor sentiment and renewable energy stock markets. Energy Econ. 2019, 84, 104564. [CrossRef]

29. Xiao, B.; Yang, Y.; Peng, X.; Fang, L. Measuring the connectedness of European electricity markets using the network topology of variance decompositions. Phys. A 2019, 535, 122279. [CrossRef]

30. Sun, Q.; An, H.; Gao, X.; Guo, S.; Wang, Z.; Liu, S.; Wen, S. Effects of crude oil shocks on the PPI system based on variance decomposition network analysis. Energy 2019, 189, 116378. [CrossRef]

31. Nakajima, T.; Toyoshima, Y. Measurement of connectedness and frequency dynamics in global natural gas markets. Energies 2019, 12, 3927. [CrossRef]

32. He, Y.; Nakajima, T.; Hamori, S. Connectedness between natural gas price and BRICS exchange rates: Evidence from time and frequency domains. Energies 2019, 12, 3970. [CrossRef]

33. Tiwari, A.K.; Nasreen, S.; Shahbaz, M.; Hammoudeh, S. Time-frequency causality and connectedness between international prices of energy, food, industry, agriculture and metals. Energy Econ. 2020, 85, 104529. [CrossRef]

34. Barbaglia, L.; Croux, C.; Wilms, I. Volatility spillovers in commodity markets: A large t-vector autoregressive approach. Energy Econ. 2020, 85, 104555. [CrossRef]

35. Guhathakurta, K.; Dash, S.R.; Maitra, D. Period specific volatility spillover based connectedness between oil and other commodity prices and their portfolio implications. Energy Econ. 2020, 85, 104566. [CrossRef]

36. Lovcha, Y.; Perez-Laborda, A. Dynamic frequency connectedness between oil and natural gas volatilities. Econ. Model. 2020, 84, 181-189. [CrossRef]

37. Zhang, W.; He, X.; Nakajima, T.; Hamori, S. How does the spillover among natural gas, crude oil, and electricity utility stocks change over time? Evidence from North America and Europe. Energies 2020, $13,727$. [CrossRef]

38. Nakajima, T. Inefficient and opaque price formation in the Japan Electric Power Exchange. Energy Policy 2013, 55, 329-334. [CrossRef]

39. Moutinho, V.; Vieira, J.; Moreira, A.C. The crucial relationship among energy commodity prices: Evidence from the Spanish electricity market. Energy Policy 2011, 39, 5898-5908. [CrossRef] 